\title{
Methodological quality and reporting of ethical requirements in clinical trials
}

Miguel Ruiz-Canela, Jokin de Irala-Estevez, Miguel Ángel Martínez-González, Enrique Gómez-Gracia and Joaquín Fernández-Crehuet University of Navarre and University of Malaga, Spain

\begin{abstract}
Objectives-To assess the relationship between the approval of trials by a research ethics committee (REC) and the fact that informed consent from participants (ICP) was obtained, with the quality of study design and methods.

Design-Systematic review using a standardised checklist.

Main measures-Methodological and ethical issues of all trials published between 1993 and 1995 in the

New England Journal of Medicine, the Lancet, the Journal of the American Medical Association and the British Medical Journal were studied. In addition, clinical trials conducted in Spain and published by at least one Spanish author during the same period in any other journal were also included. Results-We studied the published articles of 767 trials and found the following indicators of lower methodological quality to be independent predictors for failure to disclose REC approval or ICP: absence of concealment of allocation, lack of justification for unblinded trials, not using a treatment for the patients in the control group, absent information on statistical methods, not including sample size estimation, not establishing the rules to stop the trial, and omitting the presentation of a baseline comparison of groups Conclusion-Trials of higher methodological and scientific quality were more likely to provide information about their ethical aspects.

(Fournal of Medical Ethics 2001;27:172-176)
\end{abstract}

Keywords: Clinical trials; informed consent; research ethics committees; research design

\section{Introduction}

Methodological quality is the first ethical requirement in clinical trials. ${ }^{1}$ Moreover, the approval of a research ethics committee (REC) and obtaining informed consent from patients (ICP) could be considered the main issues in the ethics of research with human beings. ${ }^{2}$

Both methodological and ethical aspects should be adequately reported to enable readers to make an accurate assessment of the clinical research about which they are reading. ${ }^{3}{ }^{4}$ However, there are several studies that have found deficiencies in reporting the design and conduct of trials. . $^{5-10}$ It has also been shown that disclosure of the ICP and REC approval in published reports is sometimes incomplete, and sometimes omitted. ${ }^{11-19}$ Nevertheless, very few studies have assessed the relationship between omission of REC or ICP and methodological quality of trials. We present the main results of a systematic evaluation of 767 clinical trials where the disclosure of REC approval and ICP was assessed, as well as the association between reporting these aspects and the methodological quality of the trials.

\section{Methods}

Two short preliminary reports, including some of our methods, have been published elsewhere. ${ }^{17}{ }^{20}$ They addressed different issues from the present study. A standardised protocol was applied for reviewing every article of trials published between 1993-1995 in the New England Fournal of Medicine, the Lancet, the Fournal of the American Medical Association, and the British Medical fournal. To identify eligible articles, all issues of these journals were hand-searched. In addition, the MEDLINE bibliographic database (1993-1996) was used to identify all trials published in other journals during 1993-1995 by at least one Spanish author, for the purpose of evaluating clinical trials conducted in our country. We included every publication of experimental trials on humans that had two or more study groups ${ }^{21}$ and all studies labelled as "clinical trials", "field trials" or "randomised trials" by the authors. The exclusion criteria were: 1) nonexperimental (observational) studies; 2) studies assessing a diagnostic test to estimate its sensitivity, specificity or other validity measures; 3 ) trials published as letters to the editor or short articles, and 4) secondary analyses of previously published studies.

The standardised protocol for assessing each trial and the process of data collection were based on a checklist (available from authors) that was constructed after reviewing 43 previously published checklists. $^{22}$ After a pilot study, the selection of items to be included was performed with the help of an ad hoc expert panel. Some of the items selected were: year of publication; type of outcome to be assessed and end point(s) of the trial; number of centres participating in the study; country(ies) of origin; specialty of authors; source of funding; number of patients whose participation was requested; number of randomised participants; methods used to generate the allocation scheme and method for concealment of allocation; baseline comparison of groups; whether a hypothesis test was used in this comparison (hypothesis testing being inappropriate to exclude confounding ${ }^{23}$;) type 
of treatment and control; blinding in the assessment of outcomes; justification of opened (unblinded) trials; information on statistical methods; sample size estimation; rules and monitoring to stop the trial after interim analyses, and disclosure of REC approval and ICP.

When information on REC approval or ICP was missing in an article, we sent the corresponding authors a standardised questionnaire enquiring whether the trial had in fact been approved by an REC and whether the participants had provided informed consent. If the response was negative, we requested an explanation as to why REC approval or ICP was not obtained. After two months, we repeated the mailing to those who had not replied.

For each trial, one of us (MRC) completed the evaluation of all relevant aspects of trial design, methods and ethical issues. Another researcher (MAM) independently re-evaluated a randomly selected sample of 30 trials while blinded to the results of the first assessment. The between-raters agreement was assessed by computing the kappa index. In the subsequent evaluation, any doubt as to how to classify an item was discussed between the investigators mentioned above. Items with a kappa index less than 0.35 were not used in subsequent analyses.
A multivariable logistic regression model was fitted to assess the methodological characteristics independently related to disclosing those ethical requirements (REC/ICP). In this model, we considered the failure to report that either REC or ICP had been obtained, or the explicit disclosure in the original paper that any of these requirements were not obtained, as the outcome. Multivariable analysis was performed with the aim of controlling for several variables that could be considered as potential confounders. In addition, we considered all indicators of methodological quality with a $\mathrm{p}$ value $<0.25$ in the univariate analysis as candidate variables for the multivariable model. After including these potential predictors and/or confounders in one multivariable model, the final model was obtained by gradually removing non-significant variables using the likelihood ratio test and by evaluating potential confounding with the criterion of a $10 \%$ change between crude and adjusted estimates of the odds ratios.

Our study was not approved by an REC, nor did we request informed consent from the authors of the articles because our research did not involve an experimental design using human beings.

Table 1 Characteristics of the trials associated with not reporting any or both ethical issues (REC approval and/or request of informed consent from participants). Logistic regression analysis. Odds ratios (OR) and 95 per cent confidence intervals (CI)

\begin{tabular}{|c|c|c|c|c|}
\hline Quality indicators (number of trials) & $\begin{array}{l}\text { Proportion not } \\
\text { reporting request } \\
\text { of ICP }\end{array}$ & $\begin{array}{l}\text { Proportion not } \\
\text { reporting REC } \\
\text { approval }\end{array}$ & $\begin{array}{l}\text { Proportion not } \\
\text { reporting both } \\
\text { request of ICP and } \\
\text { REC approval }\end{array}$ & $\begin{array}{l}\text { Adjusted OR* } \\
(95 \% C I)\end{array}$ \\
\hline All sample (767) & 19.8 & 29.2 & 12.9 & \\
\hline \multicolumn{5}{|l|}{ Concealment of allocation } \\
\hline Yes $(264) \dagger$ & 14.8 & 24.2 & 8.0 & $1(\mathrm{ref}) \ddagger$ \\
\hline No $(503)$ & 22.5 & 31.8 & 15.5 & $1.66(1.12-2.46)$ \\
\hline \multicolumn{5}{|l|}{ Justification of unblinded trials } \\
\hline Yes $(36) \dagger$ & 8.3 & 19.4 & 5.6 & 1 (ref) $\ddagger$ \\
\hline No $(280)$ & 26.1 & 41.1 & 18.2 & $2.70(1.09-6.66)$ \\
\hline \multicolumn{5}{|l|}{ Type of treatment for control group } \\
\hline Placebo $(273) \dagger$ & 11.7 & 18.7 & 7.0 & 1 (ref) $\ddagger$ \\
\hline Alternative active treatment (366) & 21.3 & 33.6 & 14.5 & $1.39(0.88-2.20)$ \\
\hline No treatment $(105)$ & 35.2 & 40.0 & 21.9 & $2.47(1.37-4.47)$ \\
\hline Not a proper control group (23) & 21.7 & 34.8 & 17.4 & $1.75(0.52-5.81)$ \\
\hline \multicolumn{5}{|l|}{ Reporting of statistical methods } \\
\hline Yes: some information reported $(739) \dagger$ & 18.9 & 27.9 & 12.0 & 1 (ref)S \\
\hline No information about statistical methods (28) & 42.9 & 64.3 & 35.7 & $3.77(1.42-9.98)$ \\
\hline \multicolumn{5}{|l|}{ Sample size estimation } \\
\hline Shown $(320) \dagger$ & 14.4 & 23.1 & 6.9 & 1 (ref) \\
\hline Not shown (447) & 23.7 & 33.6 & 17.2 & $1.49(1.02-2.19)$ \\
\hline \multicolumn{5}{|l|}{ Rules to stop the trial } \\
\hline Reported (269)† & 12.1 & 21.6 & 6.4 & 1 (ref) $\ddagger$ \\
\hline Not reported (498) & 23.7 & 32.9 & 16.3 & $1.33(0.99-1.78)$ \\
\hline \multicolumn{5}{|l|}{ Baseline comparison of groups } \\
\hline Presented $(679) \dagger$ & 18.6 & 27.1 & 11.6 & 1 (ref) $\ddagger$ \\
\hline Not presented (88) & 29.5 & 45.5 & 22.7 & $1.80(1.05-3.08)$ \\
\hline \multicolumn{5}{|l|}{ Outcome } \\
\hline Survival (166)† & 22.9 & 30.7 & 13.9 & $1(\mathrm{ref}) \mathbb{S}$ \\
\hline Other (601) & 19.0 & 28.8 & 12.6 & $0.52(0.33-0.84)$ \\
\hline
\end{tabular}

Trials that acknowledged that they did not obtain the REC (Research Ethics Committee) approval or the ICP (informed consent from participants) are included together with those that did not disclose the information about these issues in the original report.

${ }^{\star} \mathrm{A}$ higher odds ratio (OR) means a higher probability of failing to provide information about either or both ethical issues in the original paper. Odds ratios have been also adjusted for journal, country of authors, length of the report, number of participants and source of funding.

$\dagger$ This was the reference category (ref: reference category)

$\neq \mathrm{p}<0.05$ (Likelihood ratio test)

$\$ \mathrm{p}<0.01$ (Likelihood ratio test) 


\section{Results}

A brief descriptive assessment of the proportion of studies failing to report the ethical requirements has been published elsewhere. ${ }^{17}$ Table 1 shows the study quality indicators that were identified in the multivariable analysis as independent predictors of failure to report information about REC approval, ICP, or both. In addition to the variables shown in the table, the analysis was also adjusted for the length of the article, the journal in which the article was published, the country of authors, the number of participants and the source of funding.

Once adjusted for the other variables, an open randomisation procedure (failure to conceal allocation) was independently associated with not presenting information on ICP and/or approval by an REC. Among open trials, those that did not justify the unblinded assessment of the outcome were more likely not to report ICP/REC. Trials which did not use a treatment for the patients in the control group omitted this information significantly more often. Not disclosing information on statistical methods, nor on sample size estimation; not providing the rules to stop the trial, and not presenting a comparison of the distribution of baseline factors were characteristics independently and more frequently associated with the omission of ICP/REC. Trials with survival of patients as the outcome were less likely to provide information about these ethical issues.
When we fitted the logistic models using the actual responses of authors to our queries (mailed questionnaires) as the outcome, and reclassified the authors who replied that they had in fact obtained the ICP/REC in spite of not having reported it, the adjusted odds ratios for most of the indicators of lower quality remained high: no justification of unblinded trials $(\mathrm{OR}=2.62)$; no information about statistical methods $(\mathrm{OR}=1.62)$; omitting sample size estimation $(\mathrm{OR}=1.34)$, and not reporting the rules to stop the trial $(\mathrm{OR}=1.43)$.

When the two ethical issues were considered as separate outcomes, all associations maintained the same direction and most of them remained consistent and statistically significant (see table 2).

\section{Discussion}

The hypothesis of this study was that the higher the methodological and scientific quality of a trial, the more attention was given to its ethical aspects. Our findings suggest that, independently of the journal where they were published and the length of the report (among other descriptive variables), trials with higher standards of quality met the requirement of reporting ethical issues more frequently. Other authors have previously assessed some of these standards as indicators of quality (concealment of allocation, ${ }^{6}$ sample size estimation, ${ }^{78}$ statistical methods, ${ }^{9}$ and justification of open trials, ${ }^{10}$ ) but have not

Table 2 Characteristics of the trials associated with not reporting either informed consent from participants or REC approval. Separated logistic regression models for reporting of each ethical issue as the outcome. Adjusted odds ratios (OR) and 95 per cent confidence intervals (CI)

\begin{tabular}{|c|c|c|c|c|}
\hline \multirow[b]{2}{*}{ Quality indicators } & \multicolumn{2}{|c|}{ Not reporting informed consent } & \multicolumn{2}{|l|}{ Not reporting REC approval } \\
\hline & Adjusted OR (95\% CI) & $p t$ & Adjusted $O R^{\star}(95 \% C I)$ & $p t$ \\
\hline Concealment of allocation & & $<0.01$ & & 0.01 \\
\hline Yes & 1 (ref) & & 1 (ref) & \\
\hline No & $1.95(1.19-3.18)$ & & $1.72(1.13-2.60)$ & \\
\hline Justification of unblinded trials & & 0.72 & & $<0.01$ \\
\hline Yes & 1 (ref) & & 1 (ref) & \\
\hline No & $1.09(0.69-1.72)$ & & $1.75(1.16-2.64)$ & \\
\hline Type of treatment for control group & & $<0.01$ & & 0.35 \\
\hline Placebo $\ddagger$ & 1 (ref) & & 1 (ref) & \\
\hline No treatment & $4.23(2.15-8.31)$ & & $1.66(0.90-3.06)$ & \\
\hline Alternative active treatment & $1.96(1.13-3.39)$ & & $1.33(0.82-2.13)$ & \\
\hline Not a proper control group & $2.59(0.64-10.47)$ & & $1.93(0.58-6.42)$ & \\
\hline Reporting of statistical methods & & 0.09 & & 0.01 \\
\hline Yes: some information reported $\ddagger$ & 1 (ref) & & 1 (ref) & \\
\hline No information about statistical methods & $2.13(0.88-5.14)$ & & $2.96(1.24-7.03)$ & \\
\hline Sample size estimation & & $<0.01$ & & 0.046 \\
\hline Shown $\ddagger$ & 1 (ref) & & 1 (ref) & \\
\hline Not shown & $1.94(1.22-3.08)$ & & $1.50(1.01-2.23)$ & \\
\hline Rules to stop the trial & & 0.12 & & 0.07 \\
\hline Reported $\ddagger$ & 1 (ref) & & 1 (ref) & \\
\hline Not reported & $1.21(0.95-1.54)$ & & $1.24(0.98-1.57)$ & \\
\hline Baseline comparison of groups & & 0.36 & & 0.03 \\
\hline Presented $\ddagger$ & 1 (ref) & & 1 (ref) & \\
\hline Not presented & $1.31(0.74-2.32)$ & & $1.85(1.09-3.14)$ & \\
\hline Outcome & & $<0.01$ & & 0.03 \\
\hline Survival & 1 (ref) & & 1 (ref) & \\
\hline Other & $0.41(0.24-0.72)$ & & $0.59(0.37-0.95)$ & \\
\hline
\end{tabular}

*Adjusted for journal, country of authors, length of the report, number of participants and source of funding. †Likelihood ratio test.

$\ddagger$ This was the reference category (ref: reference category). 
related them to ethical aspects. Our results are consistent with those of another study regarding the association between lower quality and frequent omission of reporting REC approval in studies concerning cardiopulmonary resuscitation. Nevertheless, the assessment of methodological quality in that study was only based on the randomisation scheme. ${ }^{14}$

The ethical requirements were not mentioned in some articles, even though the authors responded to our questionnaire that they had in fact requested them. However, we chose the statements in the original article (or lack thereof) over the actual response of the authors, in terms of the information provided on ICP requested or REC approval. This decision was based on several reasons: a) This may promote more reporting of ethical issues in publications of clinical trials in the future; b) Some authors did not respond to our questionnaires, and therefore we could not ascertain what they had actually done in their studies, and c) Failing to report the ethical requirements in the original article may already imply a lower concern for ethica issues in trials. ${ }^{11}$ When we fitted the logistic model using the actual responses of authors as the outcome, the adjusted odds ratios for most of the indicators of lower quality remained high. Therefore, not only the actual reporting of ethical issues in articles, but also the verified request for ICP or REC approval, showed an association with higher methodological quality.

We selected four journals that have had representatives on the International Committee of Medical Journal Editors (ICMJE) since its inception. This does not imply that these journals consistently follow the uniform requirements in al cases, but these are leading journals which publish research reports in all fields and have a broad readership. Medical journals which are published weekly also provide a large enough sample to assess the current trends in our topic of interest with precision. Reviewing trials with Spanish authors also has some advantages because it provides a subset of trials resembling a comparison ("pseudo-control") group. Most trials in this group were published in specialised journals written in English.

Our results, in which trials with higher quality standards were more likely to give attention to ethical aspects, are reassuring because readers could consider these studies as models and examples of good research. It is important to note that in certain clinical trials, obtaining ICP may be more difficult ${ }^{24}$ because of the patient's condition (ie emergency room or intensive care), or because the characteristics of the intervention may be more suitable for group rather than for individual randomisation (ie schools randomised to usual care or a special nutrition education programme). It is also possible that trials with survival of patients as the outcome omitted information about ICP/REC more often because authors considered it was implicitly assumed. However, the reasons why informed consent and REC approval were or were not obtained should always be stated.
Some authors have indicated the relevance and importance of complete reporting, as well as the importance of adequate methodological and ethical quality of clinical trials. ${ }^{125}$ This reporting should reflect both the weak and the strong aspects of researchers' work. It could be considered as evidence of the concern for ethical aspects that must be present not only during the conception, design, and conduct of the research process, ${ }^{26}$ but also in the publication and communication of results. ${ }^{27}$ The association between methodological quality and reporting of ethical requirements probably reflects the respect shown for patients during the whole research process.

\section{Acknowledgements}

We are indebted to Dr Gonzalo Herranz, Dr Alberto Ascherio, Dr Kenneth J Rothman, Dr Miguel Delgado-Rodríguez and Dr Miguel A Hernán for helpful comments and suggestions.

We thank Jane Hoashi and Rosalia Baena for the review of the English version of this manuscript.

\section{Source of support}

This work was funded by a fellowship from the Association of Friends of the University of Navarre. There are no conflicts of interest.

Miguel Ruiz-Canela, BPharm, PhD, is Associate Professor in the Department of Biomedical Humanities, $U$ niversity of Navarre, Spain. Fokin de Irala-Estevez, MD, MPH, PhD, is Professor in the Department of Epidemiology and Public Health, University of Navarre. Miguel Angel Martínez-González, MD, MPH, $P h D$, is Head of the Department of Epidemiology and Public Health, University of Navarre. Enrique GómezGracia, MD, MPH, PhD, is Professor in the Department of Preventive Medicine and Public Health, University of Malaga, Spain. Foaquin FernándezCrehuet, MD, MPH, PhD, is Head of the Department of Preventive Medicine and Public Health, University of Malaga, Spain. Address for readers' correspondence: Miguel Angel Martinez-Gonzalez, Epidemiología y Salud Pública, Irunlarrea s/n, Facultad de Medicina, Universidad de Navarra, 31080 Pamplona, Spain. Fax: (34)-48-425649; tel: (34)-48-425600; e-mail: mamartinez@unav.es

\section{References}

1 Jadad AR, Rennie D. The randomized controlled trial gets a middle-aged checkup. Fournal of the American Medical Association 1998;279:319-20.

2 Declaration of Helsinki. http://www.wma.net

3 Altman DG. Better reporting of randomised controlled trials: the CONSORT statement. British Medical fournal 1996;313: 570-1

4 Ruiz-Canela Lopez M, Aguinaga Ontoso I, Guillen Grima F, Martínez-Gonzalez MA. Publicacion de ensayos clinicos: metodo y etica. (Publishing of clinical trials: methods and ethics). Medicina Clinica (Barcelona) 1998:110:238.

5 DerSimonian R, Charette LJ McPeek B, Mosteller F Reporting methods in clinical trials. New England fournal of Medicine 1982;306:1332-7.

6 Schulz KF, Chalmers I, Hayes RJ, Altman DG. Empirical evidence of bias. Fournal of the American Medical Association 1995; 274:1456-8. 
7 Freiman JA, Chalmers TC, Smith H, Kuebler RR. The mportance of beta, the type II error, and sample interpretation of the randomized controlled trial: survey of 71 'negative' trials. New England fournal of Medicine 1978;299:690-4.

8 Moher D, Dulberg CS, Wells GA. Statistical power, sample size, and their reporting in randomized controlled trials. fournal of the American Medical Association 1994;272:122-4.

9 Pocock SJ, Hughes MD, Lee RJ. Statistical problems in the reporting of clinical trials. New England fournal of Medicine 1987;317:426-32.

10 Schulz KF, Grimes DA, Altman DG, Hayes RJ. Blinding and exclusions after allocation in randomised controlled trials: survey of published parallel group trials in obstetrics and gynaecology. British Medical fournal 1996;312:742-4.

11 Rennie D, Yank V. Disclosure to the reader of Institutional Review Board approval and informed consent. fournal of the Aeview Board approval and informed consent. Fournal of the American Medical Associat

12 Brackbill Y, Hellegers AE. Ethics and editors. Hastings Center Report 1980;10:20-2.

13 Yealy DM, Scruggs KH. Study design and pre-trial, peer review in EMS research. Prehospital and Disaster Medicine 1990;5:113-7.

14 Olson CM, Jobe KA. Reporting approval by Research Ethics Committees and subject's consent in human resuscitation research. Resuscitation 1996;31:255-63.

15 Olde Rikkert MG, ten Have HA, Hoefnagels WH. Informed consent in biomedical studies on aging: survey of four journals. British Medical fournal 1996;313:1117.

16 Matot I, Pizov R, Sprung CL. Evaluation of Institutional Review Board review and informed consent in publications of human research in critical care medicine Critical Care Medicine 1998;26:1596-602

17 Ruiz-Canela M, Martínez-González MA, Gómez-Gracia E, Fernández-Crehuet J. Informed consent and approval by Institutional Review Boards in published clinical trials. New
England fournal of Medicine 1999;340:1114-15. (Erratum New England Fournal of Medicine 1999;341:460).

18 Merz JF, Leonard DG, Miller ER. IRB review and consent in human tissue research. Science 1999;283:1647-8.

19 Karlawish JH, Hougham GW, Stocking CB, Sachs GA. What is the quality of the reporting of research ethics in publications of the quality of the reporting of research ethics in publications of ety 1999;47:76-81.

20 Ruiz-Canela M, Martínez-González MA, de Irala-Estevez J. Intention to treat analysis is related to methodological quality. British Medical fournal 2000;320:1007.

21 Rothman KJ. Modern epidemiology. Boston: Little, Brown and Company, 1986.

22 Ruiz-Canela M, Guillen-Grima F, Aguinaga I, Hernández I, Martínez-González MA. Evaluación de aspectos éticos en listas-guía de revisión de ensayos clínicos. (Evaluation of ethical issues in check-lists for reviewing clinical trials). Gaceta Sanitaria 1996;56(supp 2):120.

23 Altman DG, Dore CJ. Randomisation and baseline comparisons in clinical trials. Lancet 1990;335:149-53.

24 Smith R. Informed consent: the intricacies. British Medical fournal 1997;314:1059-60.

25 Glass KC. Toward a duty to report clinical trials: the clinical alert and beyond. Fournal of Law Medicine and Ethics 1994;22: 327-38.

26 Avins AL. Can unequal be more fair? Ethics, subject allocation, and randomised clinical trials. Fournal of Medical Ethics 1998;24:401-8.

27 Sutherland HJ, Meslin EM, Till JE. What's missing from current clinical trial guidelines? A framework for integrating science, ethics, and the community context. Fournal of Clinical Ethics 1994;5:297-303.

\title{
Narrative Based Medicine, An Interdisciplinary Conference
}

\author{
Research, Narrative, and Practice
}

A two day conference-Monday 3rd and Tuesday 4th September 2001

\section{Homerton College, Cambridge, UK}

BMF Publishing Group

For full details contact: BMA/BMJ Conference Unit, Tavistock Square, London, WC1H 9JP Tel: +44 (0)20 7383 6819; fax: +44 (0)207383 6663; email: clyders@bma.org.uk. www.quality.bmjpg.com 